\title{
OFICINA PEDAGÓGICA SOBRE EDUCAÇÃO AMBIENTAL EM RESÍDUOS SÓLIDOS URBANOS NO MUNICÍPIO DE ALFREDO MARCONDES/SP
}

\author{
Fernanda Regina Fuzzi ${ }^{1}$ \\ Daniele Carobina Santos ${ }^{2}$ \\ Antonio Cezar Leal ${ }^{3}$
}

\begin{abstract}
RESUMO
A educação ambiental em resíduos sólidos urbanos é de grande relevância, pois pode contribuir para gestão e gerenciamento dos resíduos sólidos urbanos, levando em consideração que, atualmente, muitos municípios enfrentam dificuldades e desafios para realizarem esta gestão e gerenciamento de maneira que seja adequada do ponto de vista ambiental, econômico e social. O presente artigo visa apresentar a oficina de educação ambiental em resíduos sólidos urbanos que foi realizada com alunos do ensino fundamental de uma escola pública do município de Alfredo Marcondes/SP. A realização da oficina teve como objetivo ensinar de forma lúdica os principais conceitos que estão relacionados à temática educação ambiental em resíduos sólidos urbanos com 0 intuito de sensibilizar os alunos a participarem da gestão e do gerenciamento dos resíduos sólidos urbanos, bem como, reivindicarem e contribuírem na busca por soluções para os problemas relacionados a esta gestão e gerenciamento. A participação dos alunos foi positiva e estes demonstraram bastante interesse em participar das atividades realizadas durante a oficina. A partir da realização da oficina foi possível perceber o interesse e a curiosidade dos alunos sobre os conceitos trabalhados. E a mesma também possibilitou o aprofundamento do conhecimento destes alunos referentes aos conceitos trabalhados.
\end{abstract}

PALAVRAS-CHAVE: Resíduos Sólidos Urbanos. Educação Ambiental. Alfredo Marcondes/SP.

\section{EDUCATIONAL WORKSHOP ON ENVIRONMENTAL EDUCATION IN MUNICIPAL SOLID WASTE IN THE MUNICIPALITY OF ALFREDO MARCONDES / SP}

\begin{abstract}
\footnotetext{
${ }^{1}$ Mestranda do Programa de Pós-Graduação em Geografia da Faculdade de Ciências e Tecnologia, Universidade Estadual Paulista "Júlio de Mesquita Filho" - Campus de Presidente Prudente. Bolsista do Conselho Nacional de Desenvolvimento Científico e Tecnológico - CNPq. E-mail: fernanda fr8@hotmail.com.

${ }^{2}$ Graduanda do curso de Licenciatura em Geografia da Faculdade de Ciências e Tecnologia, Universidade Estadual Paulista "Júlio de Mesquita Filho" - Campus de Presidente Prudente. E-mail: danielecarobina@gmail.com.

${ }^{3}$ Professor Doutor do Departamento de Geografia da Faculdade de Ciências e Tecnologia, Universidade Estadual Paulista "Júlio de Mesquita Filho" - Campus de Presidente Prudente. Pesquisador PQ/CNPq. E-mail: cezar@fct.unesp.br.
} 
Environmental education about municipal solid waste is of great importance because it can contribute to administration and management of municipal solid waste, taking into account that currently many municipalities face difficulties and challenges to accomplish that administration and management, in a way that is appropriate of the view environmental, economic and social. This article presents the environmental education workshop on municipal waste which was conducted with elementary school students from a public school in the city of Alfredo Marcondes / SP. The holding of the workshop aimed to teach in a playful manner the key concepts that are related to the theme environmental education in municipal solid waste in order to sensitize the students to participate in the administration and management of municipal solid waste as well as claim and contribute in the search for solutions to the problems related to this administration and management. The participation of the students was positive and they showed great interest in participating in the activities carried out during the workshop. As low the realization of the workshop it was revealed the interest and curiosity of the students on the concepts worked. In this article also made it possible to deepen the knowledge of these students regarding the concepts worked.

KEYWORDS: Municipal Solid Waste. Environmental Education. Alfredo Marcondes / SP.

\title{
TALLER EDUCATIVO DE EDUCACIÓN AMBIENTAL EN RESIDUOS SÓLIDOS URBANOS EN EL MUNICIPIO DE ALFREDO MARCONDES / SP
}

\begin{abstract}
RESUMEN
Educación ambiental en los residuos sólidos urbanos es de gran importancia, ya que puede contribuir a la gestión y el manejo de los residuos sólidos urbanos, teniendo en cuenta que en la actualidad, muchos municipios se enfrentan a dificultades y desafíos para lograr esto la administración y gestión de medio punto apropiado vista ambiental, económico y social. Este artículo presenta el taller de educación ambiental sobre los residuos municipales que se realizó con estudiantes de primaria de una escuela pública en la ciudad de Alfredo Marcondes / SP. La celebración del taller tuvo como objetivo enseñar de una manera lúdica los conceptos clave que se relacionan con el tema de la educación ambiental en los residuos sólidos urbanos con el fin de sensibilizar a los estudiantes a participar en la gestión y manejo de los residuos sólidos urbanos, así como reclamo y contribuir en la búsqueda de soluciones a los problemas relacionados con esta administración y gestión. La participación de los alumnos fue positiva y se mostró un gran interés en participar en las actividades llevadas a cabo durante el taller. Desde el día del taller se reveló el interés y la curiosidad de los estudiantes sobre los conceptos trabajados. Y lo mismo también ha permitido profundizar en el conocimiento de estos estudiantes sobre los conceptos trabajó .
\end{abstract}

PALABRAS CLAVE: Residuos Sólidos Urbanos. Educación Ambiental. Alfredo Marcondes/SP.

\section{INTRODUÇÃO}

As atividades humanas sempre resultaram na geração de resíduos sólidos. Sendo assim, desde as sociedades primitivas o homem gera resíduos em suas atividades diárias. Nestas sociedades os resíduos gerados eram basicamente orgânicos. O processo industrialização e o aumento da população mundial resultaram em um aumento significativo na quantidade de resíduos sólidos gerados e em uma mudança nos tipos destes, ou seja, a geração de resíduos sólidos que era 


\section{Periódico Eletrôntico

basicamente de orgânicos passa a ser consideravelmente de inorgânicos e com muitos deles apresentando grande potencial de ocasionar problemas ambientais.

Atualmente, é possível observar um aumento considerável da população urbana dos municípios brasileiros e que este processo de urbanização, na maioria das vezes, não vem acompanhado de um planejamento urbano adequado. $O$ que contribui para que gestores públicos e a população de muitos destes municípios estejam enfrentando inúmeros problemas e desafios na gestão e gerenciamento de seus resíduos sólidos urbanos. De maneira geral, tais problemas, estão relacionados: à coleta; a dificuldade em se oferecer uma destinação final ambientalmente adequada aos resíduos sólidos; uma disposição final ambientalmente adequada para os rejeitos e aos prejuízos socioambientais decorrentes da disposição final inadequada (como por exemplo, a que é realizada em lixões). E superá-los consiste em um grande desafio para os gestores públicos e para população em geral.

Neste contexto, a educação ambiental em resíduos sólidos faz-se de grande relevância, pois através dela é possível sensibilizar as pessoas sobre os problemas que estão relacionados aos resíduos que elas geram em suas atividades diárias. 0 que pode contribuir para que elas se conscientizem da necessidade de buscarem soluções para tais problemas, bem como de "cobrarem" dos gestores públicos uma melhora na gestão e gerenciamento destes resíduos sólidos urbanos.

Levando em consideração à importância que acreditamos que a educação ambiental em resíduos sólidos possui, o presente artigo visa apresentar uma oficina de educação ambiental que foi desenvolvida com alunos do ensino fundamental da escola "Filomena Scatena Christofano", localizada no município de Alfredo Marcondes. Este município está localizado a oeste do estado de São Paulo e, segundo o Censo do IBGE (2000), conta com uma população de 3. 891 habitantes. No município são gerados e coletados aproximadamente $1.935 \mathrm{Kg} /$ dia de resíduos sólidos domiciliares, totalizando cerca de 58,050 Ton/mês (conforme informações disponibilizadas na Prefeitura do município de Alfredo Marcondes). O município possui coleta seletiva e uma associação de catadores de materiais recicláveis a ASCAM (Associação de catadores de Alfredo Marcondes) que fazem parte da COOPEREDES (Cooperativa de Trabalho de Redes de Alfredo Marcondes), que existe desde 2009. Nesta associação trabalham em média de 12 a 15 catadores. 
As atividades realizadas nesta escola buscaram levar em consideração a realidade do município que estes alunos vivem e buscaram sempre apresentar exemplos próximos ao cotidiano destes alunos. Acredita-se que esta seja uma maneira de sensibilizá-los sobre a importância de que participem e contribuam na busca de soluções para uma melhor gestão e gerenciamento dos resíduos sólidos urbanos em seu município.

\section{EDUCAÇÃO AMBIENTAL EM RESÍDUOS SÓLIDOS URBANOS}

Há múltiplas definições para educação ambiental. A maioria delas frisa que é um processo de aprendizagem e comunicação das questões relacionadas com a interação dos seres humanos com o ambiente, tanto em âmbito global, natural, como criado pelo homem (RODRIGUEZ; SILVA, 2013). Segundo a Política Nacional de Educação Ambiental:

Entende-se por educação ambiental os processos por meio dos quais o
indivíduo e a coletividade constroem valores sociais, conhecimentos,
habilidades, atitudes e competências voltadas para a conservação do meio
ambiente, bem de uso comum do povo, essencial à sadia qualidade de vida
e sua sustentabilidade (BRASIL, 1999).

Rodriguez; Silva (2013) defendem que a educação ambiental deve formar valores ambientais, ou valores verdes, e que estes são muito diferentes dos chamados valores da modernidade. Estes autores definem como valores ambientais: a harmonia com a natureza; a sociedade comunitária e cooperativa; o crescimento econômico balanceado dentro dos limites da natureza; a participação e consulta cidadã, etc. Em contrapartida, definem os valores da modernidade como: o domínio da natureza; o individualismo agressivo; o crescimento econômico ilimitado; a dependência dos especialistas; entre outros.

Observa-se que através da educação ambiental indivíduos e sociedade constroem valores de conservação ao meio ambiente que estes devem ser pautados, por exemplo, na utilização dos recursos naturais de maneira consciente. $E$ que a construção de valores ambientais é de extrema importância principalmente na sociedade atual que é, na maioria das vezes, pautada em valores individualista, de crescimento econômico ilimitado e de exploração dos recursos naturais.

Ao se referir à educação ambiental em resíduos sólidos, tem-se que esta está relacionada a: 
Educação ambiental relativa à geração e ao descarte de resíduos decorrentes das atividades humanas em geral, exercidas direta e indiretamente pelo cidadão comum, para o provimento de atividades consideradas necessárias. Na medida em que educação ambiental implica em discutir integradamente conhecimentos, valores e participação politica, a abordagem da questão dos resíduos deve incluir com destaque a atividade de consumo de produtos e serviços, em análises que busquem distinguir necessidades básicas do ser humano, voltadas para objetivos essenciais, de necessidades criadas pelo ser humano, voltadas para objetivos artificiais, tendo sempre como parâmetros as referências socioambientais que condicionam a realidade contemporânea e suas implicações para com as gerações futuras (LOGAREZZI, 2004).

A partir disto pode-se dizer que a educação ambiental em resíduos deve ser pautada no consumo consciente (comprar somente o necessário e não coisas que não precisamos, mas que somos induzidos a comprá-las), e em princípios de não geração, redução, reutilização e reciclagem e sempre nos preocupando que os resíduos sólidos que geramos podem impactar não só a nossa geração como também as gerações futuras.

Acredita-se que a escola seja um dos meios indispensáveis para se conseguir desenvolver atividades de educação ambiental. Neste sentido, Cantoia (2007) afirma que é fundamental que a Educação Ambiental faça parte dos currículos escolares e deste modo às escolas podem ser locais nos quais é possível disseminarem-se novas ideias e produzir-se conhecimento.

Para Oliveira; et al. (2006) a escola exerce o papel de proporcionar ao aluno o conhecimento e a compreensão dos problemas ambientais existentes no meio em que vivemos. Isso mostra que Educação Ambiental produz um diálogo constante entre percepções sobre o conhecimento, a aprendizagem, o ensino, a sociedade e o ambiente (JACOBI, 2003).

\section{CONCEITOS BÁSICOS SOBRE RESÍDUOS SÓLIDOS URBANOS TRABALHADOS DURANTE A OFICINA}

Ao se trabalhar com educação ambiental em resíduos sólidos urbanos alguns conceitos são de fundamental importância. Para início de conversa iremos trabalhar os conceitos de lixo e resíduos sólidos. Entende-se como lixo o:

[...] que sobrou de uma atividade qualquer e é descartado sem que seus valores (sociais, econômicos e ambientais) potenciais sejam preservados, incluindo não somente resíduos inservíveis, mas também, incorretamente do ponto de vista ambiental, resíduos reutilizáveis e recicláveis (LOGAREZZI, 2004). 
A oficina visou demostrar que muito daquilo que é simplesmente descartado pelos alunos possui valores sociais, econômicos e ambientais e que estes valores devem ser preservados. Neste sentido, o termo mais adequado a ser utilizado é o termo resíduo, que consiste no "[...] que sobra de uma atividade qualquer, natural ou cultural. Nas atividades humanas em geral, geramos resíduos (e não lixo)" (LOGAREZZI, 2004). Nesta oficina, optamos por trabalhar com o conceito resíduo sólido e nos baseamos na definição apresentada pela Política Nacional de Resíduos Sólidos, esta define resíduos sólidos como:

[...] material, substância, objeto ou bem descartado resultante de atividades humanas em sociedade, a cuja destinação final se procede, se propõe proceder ou se está obrigado a proceder, nos estados sólido ou semissólido, bem como gases contidos em recipientes e líquidos cujas particularidades tornem inviável o seu lançamento na rede pública de esgotos ou em corpos d'água, ou exijam para isso soluções técnica ou economicamente inviáveis em face da melhor tecnologia disponível (BRASIL, 2010).

Atualmente, muitos municípios brasileiros enfrentam inúmeras dificuldades e desafios para realizarem a gestão e o gerenciamento dos resíduos sólidos gerados por seus moradores, principalmente para que estes sejam realizados de modo adequado do ponto de vista ambiental, econômico e social. Entende-se por gestão integrada de resíduos sólidos o "conjunto de ações voltadas para a busca de soluções para os resíduos sólidos, de forma a considerar as dimensões política, econômica, ambiental, cultural e social, com controle social e sob a premissa do desenvolvimento sustentável" (BRASIL, 2010). E o termo gerenciamento dos resíduos sólidos se refere:

[...] aos aspectos tecnológicos e operacionais da questão, envolvendo fatores administrativos, gerenciais, econômicos, ambientais e de desempenho: produtividade e qualidade, por exemplo, e relaciona-se à prevenção, redução, segregação, reutilização, acondicionamento, coleta, transporte, tratamento, recuperação de energia e destinação final de resíduos sólidos (SCHALCH et al, 2002).

Na gestão e gerenciamento de resíduos sólidos, de acordo com a Política Nacional de Resíduos Sólidos, deve ser observada a seguinte ordem de prioridade: não geração, redução, reutilização, reciclagem, tratamento dos resíduos sólidos e disposição final ambientalmente adequada dos rejeitos.

Os alunos foram orientados sobre a importância da prática dos 3R (Reduzir, Reutilizar e Reciclar) em suas atividades diárias. Logarezzi (2004) coloca que:

[...] antes de ser gerado um resíduo pode ser evitado como conseqüência de revisão de alguns hábitos (por exemplo, copo plástico pode deixar de ser gerado como resíduo quando, em certos âmbitos, se faz uso de copo/caneca durável - primeiro $\mathrm{R}$ - redução); antes de ser descartado um 
resíduo pode deixar de ser resíduo se a ele for atribuída uma nova função (por exemplo, um pote de azeitona pós-uso pode ser usado para armazenar óleo de fritura e garrafas plásticas pós-uso podem ser usadas para composições artísticas - segundo $\mathrm{R}$ - reutilização) ou se sua função original for cumprida por mais um tempo em um novo contexto (por exemplo, um calçado considerado inútil/sobra para uma pessoa pode ainda ser útil para outra - segundo R); ao ser descartado um resíduo pode ter seu "status" de resíduo (que contém valores sociais, econômicos e ambientais) preservado, ao longo do que pode ser chamada de rota dos resíduos, a qual geralmente envolve descarte e coleta seletivos - terceiro $R$ - reciclagem; caso contrário, um resíduo pode, por meio do descarte comum, virar lixo - nenhum dos $3 R$ (LOGAREZZI, 2004).

Pode-se dizer que Reduzir, consiste no fato de que é necessário diminuir a quantidade de resíduos sólidos que geramos em nossas atividades diárias. É importante observar se aquilo que vamos jogar no lixo, possui alguma outra utilidade para nós, ou se pode ser útil à outra pessoa, isso se chama Reutilizar. A Política Nacional de Resíduos Sólidos define reutilização como: "processo de aproveitamento dos resíduos sólidos sem sua transformação biológica, física ou físico-química” (BRASIL, 2010). Muitos resíduos sólidos descartados podem ser reciclados, entende-se por reciclagem o "processo de transformação dos resíduos sólidos que envolve a alteração de suas propriedades físicas, físico-químicas ou biológicas, com vistas à transformação em insumos ou novos produtos" (BRASIL, 2010).

A Política Nacional de Resíduos Sólidos menciona que os resíduos sólidos depois de esgotados todas as possibilidades de tratamento e recuperação por processos tecnológicos disponíveis e economicamente viáveis, estes passam a ser chamados de rejeitos e não apresentam outra possibilidade que não a disposição final ambientalmente adequada que consiste na: "distribuição ordenada de rejeitos em aterros, observando normas operacionais específicas de modo a evitar danos ou riscos à saúde pública e à segurança e a minimizar os impactos ambientais adversos" (BRASIL, 2010). No Brasil, infelizmente não são apenas os rejeitos que vão para os locais de disposição final, muitos resíduos sólidos também vão parar nestes locais diminuindo sua vida útil destes. E estes locais de disposição final, na maioria das vezes, não são ambientalmente adequados.

Foram apresentados aos alunos os conceitos de: aterro sanitário, aterro controlado e lixão que consistem em formas comuns de disposição dos resíduos sólidos e rejeitos no Brasil. Aterro sanitário é o modo ambientalmente adequado para a disposição final dos rejeitos, pois consiste em:

[...] um método para disposição final dos resíduos sólidos urbanos, sobre terreno natural, através do seu confinamento em camadas cobertas com material inerte, geralmente solo, segundo normas operacionais específicas, de modo a evitar danos ao meio ambiente, em particular à saúde e à segurança pública (MONTEIRO, 2001). 
Os aterros controlados consistem, segundo Jardim et al (1995), em uma técnica de disposição de resíduos sólidos urbanos no solo, sem causar danos ou riscos à saúde pública e a sua segurança, minimizando os impactos ambientais. De acordo com Albuquerque (2012) a diferença básica entre um aterro sanitário e um aterro controlado é que no primeiro é obrigatório a coleta e o tratamento do chorume, assim como da drenagem e queima do biogás.

No que se refere aos lixões este são "[...] locais onde o lixo coletado é lançado diretamente sobre o solo sem qualquer controle e sem quaisquer cuidados ambientais, poluindo tanto o solo, quanto o ar e as águas subterrâneas e superficiais das vizinhanças" (MONTEIRO, 2001). Segundo Albuquerque (2012) os lixões consistem em uma maneira de disposição completamente inadequada, pois se caracterizam pela simples descarga do lixo sobre o solo, sem medidas de proteção ao meio ambiente ou à saúde pública.

Os catadores de materiais recicláveis são pessoas que vivem da comercialização dos resíduos que podem ser reciclados. Vale mencionar que atualmente é comum observar a organização destes catadores em associações ou cooperativas de catadores de materiais recicláveis. Foi apresentado aos alunos o que são cooperativas e associações de catadores e discutidos como estas formas de organizações oferecem condições melhores, mais dignas e legalizadas de trabalho aos catadores de materiais recicláveis. Para que estes estabelecimentos obtenham maior ganho é importante que os resíduos sólidos que cheguem até eles sejam materiais recicláveis e que estes não venham misturados com matéria orgânica. Para isso é fundamental que sejam realizados o descarte seletivo e a coleta seletiva. Entende-se por descarte seletivo:

[...] a atitude de descartar resíduos inevitavelmente gerados, preservando sua potencialidade de reaproveitamento, o que implica identificação e separação de itens considerados recicláveis secos em meio aqueles que são considerados inservíveis, no contexto em questão. Essa atitude exige ao menos dois coletores distintos e duas vias de coleta e encaminhamento dos resíduos assim descartados separadamente (LOGAREZZI, 2006, p.101).

E por coleta seletiva a: "[...] coleta de resíduos sólidos previamente segregados conforme sua constituição ou composição" (BRASIL, 2010, p. 2). Observa-se que aos alunos cabe realizar o descarte seletivo em suas casas e colocar os materiais recicláveis para serem recolhidos pela coleta seletiva e que "a escola tem um papel fundamental em difundir a ideia da necessidade do descarte seletivo e da coleta seletiva na cidade" (CANTOIA, 2007). 


\section{OBJETIVOS}

A realização desta oficina teve como objetivos:

- Trabalhar com os alunos os principais conceitos relacionados à temática educação ambiental em resíduos sólidos urbanos;

- Ensinar de forma lúdica (através de músicas, brincadeiras, etc.) questões referentes à temática resíduos sólidos urbanos, buscando a participação e criatividade dos alunos durante a realização das atividades;

- Sensibilizar os alunos sobre a importância de participarem da gestão e do gerenciamento dos resíduos sólidos urbanos, bem como, reivindicarem e contribuírem na busca por soluções para os problemas relacionados a esta gestão e gerenciamento, pois estas não são obrigações somente dos gestores públicos, mas também da população em geral;

\section{METODOLOGIA}

Para a elaboração da oficina, alguns procedimentos metodológicos foram necessários, tais como: levantamento e revisão bibliográfica em livros; monografias; dissertações e teses que abordassem assuntos relacionados à temática educação ambiental em resíduos sólidos (este material nos ofereceu subsídio teórico para elaboração da oficina); pesquisas em web sites que ofereceram materiais que subsidiaram a elaboração das atividades realizadas através da oficina e em páginas de instituições, como por exemplo, o Instituto Brasileiro de Geografia e Estatística (IBGE), dentre outros sites que ofereceram informações relevantes para a preparação da oficina e a elaboração do material educativo a ser trabalhado na escola.

As atividades desenvolvidas durante a oficina foram pensadas e propostas de modo que partimos daquilo que os alunos sabiam sobre as temáticas relacionadas à educação ambiental em resíduos sólidos para avançarmos no ensino destas temáticas, as atividades foram realizadas de forma lúdica para facilitar o processo de ensinoaprendizagem. A seguir, estão descritas as atividades que foram realizadas e as metodologias por elas utilizadas:

Atividade 1: "Conhecendo os conceitos".

Materiais necessários: folhas de sulfite com os conceitos impressos. 
$\mathrm{Na}$ primeira atividade proposta, intitulada "Conhecendo os conceitos", os alunos foram organizados em formato de um círculo, os conceitos impressos em folhas de sulfite foram espalhados (virados para baixo) dentro deste círculo, como é possível observar na figura 1. Os alunos foram orientados em escolher uma folha, virá-la e fazer a leitura de qual conceito nela estava escrito (por exemplo, coleta seletiva). Ou ler cada conceito eles eram questionados sobre o que achavam que significava esse conceito ("O que vocês acham que é coleta seletiva"?) e se achavam que tal conceito estava relacionado com resíduos sólidos (Vocês acham que coleta seletiva tem alguma coisa relacionada com resíduos sólidos?). Em seguida, foi pedido que um aluno fizesse a leitura do que significava aquele conceito e o mesmo era explicado e discutido com os alunos.

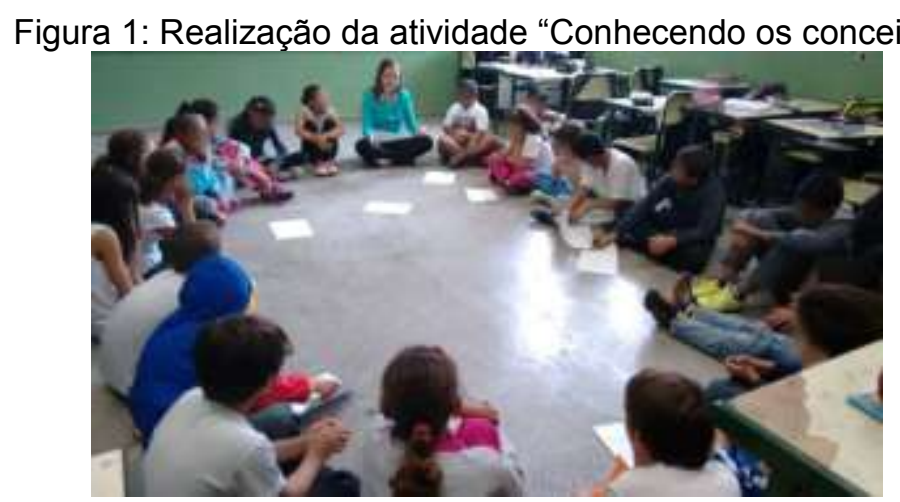

Fonte: FUZZI, SANTOS, 2015.

Nesta atividade foram trabalhados os seguintes conceitos: lixo; resíduos sólidos; redução; reutilização; reciclagem; descarte seletivo; coleta seletiva; cooperativas e associações de catadores de materiais recicláveis; aterro sanitário; aterro controlado e lixão.

Atividade 2: "Hora da música"

Materiais necessários: letra da música e aparelho de reprodução de áudio.

$\mathrm{Na}$ segunda atividade que foi realizada, intitulada "Hora da música", foram distribuídas para os alunos a letra da música "A Coleta Seletiva e a Reciclagem" que foi retirada do site "Palco da Reciclagem: A Arte de Reciclar Contando Histórias". Foi realizada a leitura da letra da música com os alunos e, em seguida, a mesma foi reproduzida algumas vezes, os alunos foram orientados a prestarem atenção na letra da música e também puderam cantá-la. Após ouvirem a música (no mínimo três vezes) eles foram instigados a refletirem sobre a letra da mesma. Foram levantadas e discutidas questões como: "Vocês gostaram da música?" "Sobre o que a letra da música fala?" "Quais conceitos que trabalhamos que foram abordados na música?" "Porque é importante separar os resíduos sólidos?". Estas questões foram propostas aos alunos com o intuito de nortear a reflexão da letra da música. 
Atividade 3: "Hora da triagem - vamos separar os materiais recicláveis dos não recicláveis".

Materiais necessários: recipientes pré-identificados com etiquetas de reciclável e não reciclável e imagens impressas de resíduos sólidos que os alunos geram em seu cotidiano e que podem ou não serem reciclados.

Nesta atividade, intitulada "Hora da triagem - vamos separar os materiais recicláveis dos não recicláveis", os alunos foram divididos em dois grupos (G1 e G2) e foram mostradas figuras de resíduos sólidos que eles geram em seu cotidiano, como é possível observar na figura 2, e os grupos de forma alternada foram questionados se estes resíduos eram ou não recicláveis e para qual recipiente deveriam ser destinados, e então, eram colocados no recipiente correto. Por fim, eles foram informados que esta atividade consiste em uma simulação de como devem realizar o descarte seletivo em suas casas e foram alertados sobre a importância que este seja realizado de maneira correta.

Figura 2: Realização da atividade "Hora da triagem - vamos separar os materiais recicláveis dos não

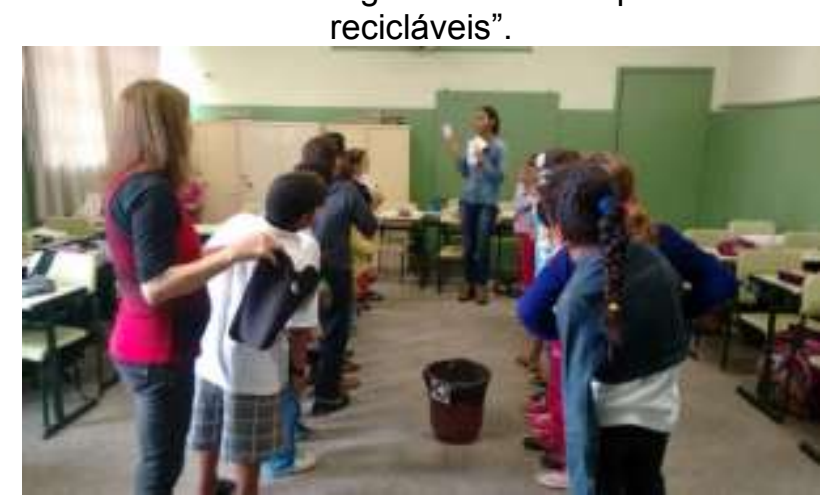

Fonte: FUZZI, SANTOS, 2015.

Atividade 4: "Hora de colorir!"

Materiais necessários: figuras relacionadas à temática educação ambiental em resíduos sólidos urbanos.

Nesta atividade foram entregues aos alunos figuras relacionadas à coleta seletiva, redução, reutilização e reciclagem dos resíduos sólidos ${ }^{4}$ e foi solicitado para que eles realizassem o que estava sendo pedido no enunciado da figura e que a colorissem. A figura 3 retrata os alunos sendo orientados de como deveriam realizar esta atividade e a figura 4 é um exemplo de uma atividade já pronta realizada por um dos alunos.

Figuras 3 e 4: Realização da atividade "Hora de colorir!"

\footnotetext{
${ }^{4}$ As figuras utilizadas nesta atividade foram retiradas de web sites que estão devidamente referenciados em nossas Referências.
} 


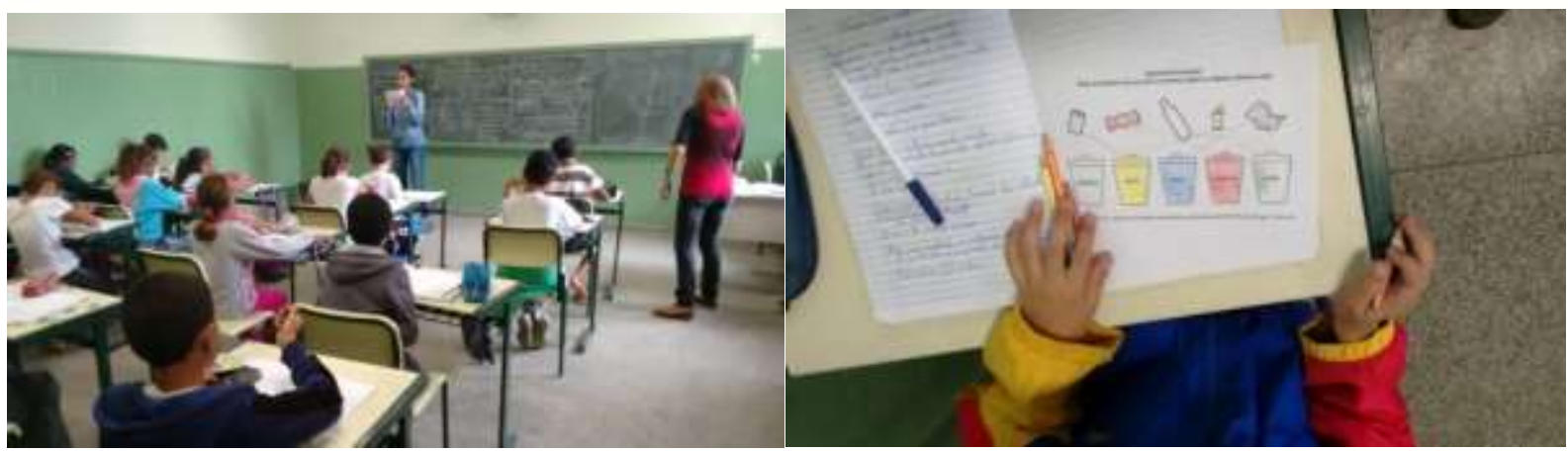

Fonte: FUZZI, SANTOS, 2015.

Fonte: FUZZI, SANTOS, 2015.

\section{RESULTADOS}

A participação dos alunos foi positiva e estes demonstraram bastante interesse em participar das atividades realizadas durante a oficina. Em uma das salas no começo eles estavam meio tímidos, mas depois com incentivo da professora começaram participar mais e a fazer perguntas.

Vale mencionar que foi interessante o fato de que quando estávamos terminando de realizar nossas atividades, em uma das salas, os alunos tinham um tempo para utilizarem a sala de informática e foi possível observar que muitos deles começaram a pesquisar sobre conceitos trabalhados durante a oficina (como exemplos: reciclagem e resíduos sólidos orgânicos), como mostra as figuras 5 e 6 . O que nos revelou o interesse destes alunos pelas temáticas trabalhadas. Aproveitamos esse momento na sala de informática para auxilia-los em suas pesquisas e solucionar possíveis dúvidas.

Figuras 5 e 6: Alunos pesquisando na internet sobre conceitos trabalhados pela oficina.
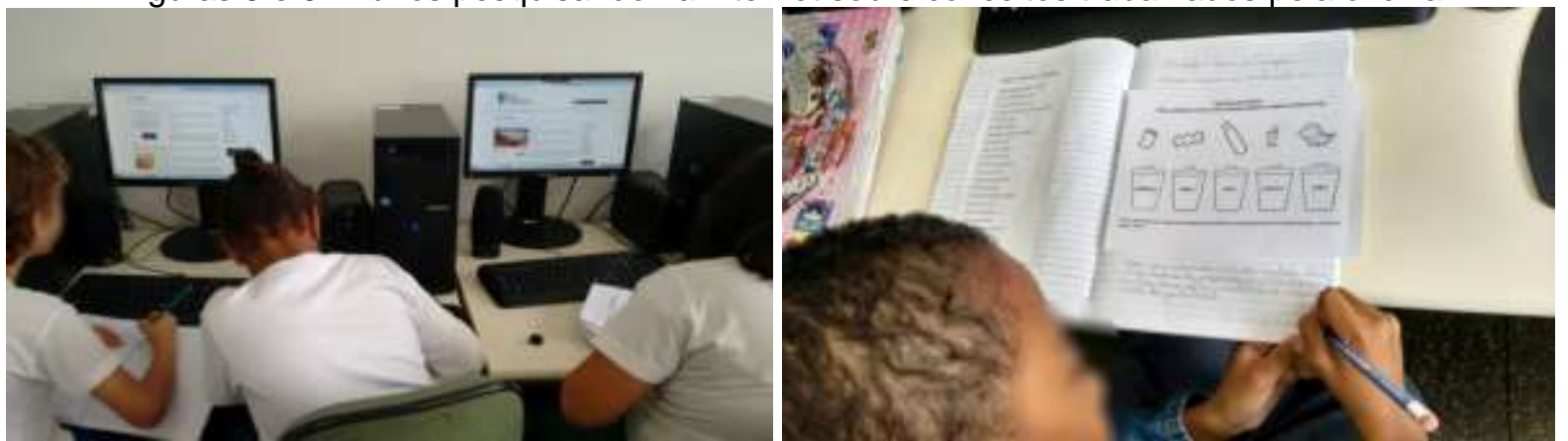

Fonte: FUZZI, SANTOS, 2015.

Fonte: FUZZI, SANTOS, 2015.

E na atividade: "Hora da triagem - vamos separar os materiais recicláveis dos não recicláveis" os alunos demostraram bastante conhecimento do que era ou não reciclável.

\section{CONCLUSÃO}

A realização da oficina foi de grande relevância, pois através do conhecimento por ela transmitido foi possível sensibilizar os alunos para questões e conceitos relacionados à 
temática educação ambiental em resíduos sólidos urbanos por ela trabalhados. Como todos somos geradores de resíduos, buscar soluções para questões relacionadas a esta temática, não cabe apenas aos gestores públicos, mas também a população em geral.

A partir da realização da oficina foi possível perceber o interesse, bem como, a curiosidade dos alunos sobre os conceitos trabalhados. E a mesma também foi importante, pois possibilitou o aprofundamento do conhecimento destes alunos referentes a estes conceitos.

Acreditamos que ficou faltando uma atividade que os alunos preparassem algum material para expor na escola, tais como, confecção de objetos feitos de materiais recicláveis e/ou elaboração de um painel com paródias, desenhos, poesias, etc. (feitos pelos próprios alunos de acordo com suas habilidades) referente às temáticas trabalhadas. Pois esta atividade estava prevista quando elaboramos a oficina, mas não foi possível de ser realizada no tempo que nos foi disponibilizado.

Vale mencionar que fomos bem recebidos pelos funcionários, professores e alunos da escola. As professoras disseram gostar muito da oficina e demonstraram solicitas para realização de outras oficinas. É possível dizer que o interesse de uma das professoras foi grande, visto que, a mesma perguntou se tínhamos mais atividades preparadas e informamos sobre a confecção de objetos e da realização de atividades pelos alunos para elaboração de um painel, mas que não haviam sido realizadas, pois exigiam um pouco mais de tempo. Esta professora nos informou a possibilidade de ajustar o cronograma para nos disponibilizar um tempo para realização destas atividades durante a semana do meio ambiente. E a outra mencionou o fato de que deveríamos preparar mais atividades para realizar com os alunos.

Por fim, cabe ressalta que a oficina foi enriquecedora para nós que a realizamos, pois nos possibilitou um contato direto com os alunos. Isto porque, além de realizarmos pesquisas sobre a temática resíduos sólidos somos uma graduanda e uma formada no curso de Licenciatura em Geografia e a experiência de trabalhar com alunos além de enriquecedora é importante para nossa formação que acreditamos ser algo contínuo, mesmo após terminar a graduação.

\section{REFERÊNCIAS}

ALBUQUERQUE, J. B. T. de. Resíduos Sólidos. 1. ed. Leme: Independente, 2012. 796 p.

BRASIL. Lei no. 9.795, de 27 de Abril de 1999. Dispõe sobre a educação ambiental, institui a Política Nacional de Educação Ambiental e dá outras providências. 1999. Disponível em < http://www.planalto.gov.br/ccivil_03/Leis/L9795.ht>. Acesso em: 05 de Novembro de 2012. 
BRASIL. Lei o 12.305, de 2 de agosto de 2010. Institui a Política Nacional de Resíduos Sólidos; altera a Lei no 9.605, de 12 de fevereiro de 1998; e dá outras providências. Brasília, 2010. Disponível em: <http://www.planalto.gov.br/ccivil_03/_ato2007-

2010/2010/lei/l12305.htm>. Acesso em: 10 set. 2013.

CANTÓIA, S. F. Educação ambiental e coleta seletiva em Presidente Prudente - SP: avaliando seus resultados no Conjunto Habitacional Ana Jacinta. 2007. Dissertação (Mestrado em Geografia) Faculdade de Ciências e Tecnologia, Universidade Estadual Paulista, Presidente Prudente, 2007.

FIGURA PARA COLORIR. Disponível em: <http://www.megalix.com.br/kids/wpcontent/uploads/2011/01/lixeira-02.jpg>. Acesso em: 06 mai. 2015.

FIGURAS PARA COLORIR. Disponível em: < https://colorindodesenhos.wordpress.com/2012/03/22/atividades-e-desenhos-sobre-a-poluicao-paracolorir/ >. Acesso em: 06 mai. 2015.

IBGE - Instituto Brasileiro de Geografia e Estatística. Sinopse do Censo Demográfico 2010. Disponível em: <http://www.ibge.gov.br/censo2010/primeiros_dados_divulgados/index.php>. Acesso em: 06 mai. 2015.

JACOBI, P. Educação Ambiental, cidadania e sustentabilidade. Cadernos de Pesquisa. $N^{\circ} 118$. São Paulo, 2003.

JARDIM, N.S. et al. Lixo Municipal: manual de gerenciamento integrado. 1. ed. São Paulo: Instituto de Pesquisas Tecnológicas: CEMPRE, 1995. 278 p.

LOGAREZZI, A. Contribuições Conceituais para o Gerenciamento de Resíduos Sólidos e Ações de Educação Ambiental. In: LEAL, A. C. et al. Resíduos sólidos no Pontal do Paranapanema. 18. ed. Presidente Prudente: [s.n.], 2004. 280 p.

LOGAREZZI. A. Educação Ambiental em resíduo: uma proposta de terminologia. In:

Consumo e Resíduo - Fundamentos para o trabalho educativo. São Carlos: EdUFSCAR, 2006, 216 p.

MONTEIRO, J.H.P. et al. Manual de Gerenciamento Integrado de resíduos sólidos. 15. ed. Rio de Janeiro: IBAM, 2001. 200 p. Disponível em: <http://www.resol.com.br/cartilha4/manual.pdf>. Acesso em: 03 nov. 2014.

MÚSICA: "A Coleta Seletiva e a Reciclagem". In: Palco da Reciclagem: A Arte de Reciclar Contando Histórias. Disponível em: < http://www.palcodareciclagem.com.br/?cat=5>. Acesso em: 01 nov. 2014.

OLIVEIRA, M.; OLIVEIRA, B.; VILELA, M. C. CASTRO, T. A. A importância da Educação Ambiental na Escola e a Reciclagem do lixo orgânico. Revista Científica sociais aplicadas da EDUVALE. Ano V, № 07. Vale de São Lourenço- Jaciara/MT, novembro 2006.

RODRIGUEZ, J. M. M.; SILVA, E. V. Educação Ambiental e Desenvolvimento Sustentável:

Problemática, Tendências e Desafios. 3. ed. Fortaleza: Expressão Gráfica e Editora, 2013. 244 p.

SCHALCH, Valdir [et al.]. Gestão e Gerenciamento de Resíduos Sólidos. São Carlos:

Universidade de São Paulo, Escola de Engenharia de São Carlos e Departamento de Hidráulica e Saneamento, 2002. Disponível em < http://www.deecc.ufc.br/Download/Gestao_de_Residuos_Solidos_PGTGA/Apostila_Gestao_ e_Gerenciamento_de_RS_Schalch_et_al.pdf>. Acesso em: 20 set. 2012. 